\title{
La lectura del libro álbum como mediación hacia el desarrollo socioemocional
}

\author{
Reading Picture- \\ Books as a \\ Mediation Towards \\ Social-Emotional \\ Development
}

A leitura do livro-álbum como mediação para o desenvolvimento socioemocional
Karen Lorena Rodríguez Turriago* https://orcid.org/0000-0002-8770-9383

Zahyra Camargo Martínez** https://orcid.org/0000-0002-5589-4473

Graciela Uribe Álvarez*** https://orcid.org/0000-0003-0450-2174
Magíster en Educación de la Universidad del Cauca. Docente Institución Educativa Normal Superior María Inmaculada, Caicedonia, Colombia. Doctoranda en Ciencias de la Educación, línea de investigación en Didáctica de la Lengua Materna y la Literatura.

Correo: klrodriguezt@uqvirtual.edu.co

** Directora de la Maestría y el Doctorado en Ciencias de la Educación de la Universidad del Quindío. Profesora titular. Doctora en Didáctica de las Lenguas y la Literatura por la Universidad Complutense de Madrid. Investigadora en el área de Didáctica de la Lengua Materna.

Correo: zcamargo@uniquindio.edu.co

*** Profesora de la Licenciatura en Literatura y Lengua Castellana y de la Maestría y el Doctorado en Ciencias de la Educación de la Universidad del Quindío. Profesora asociada. Doctora en Didáctica de las Lenguas y la Literatura por la Universidad Complutense de Madrid. Investigadora en el área de Didáctica de la Lengua Materna y la Literatura.

Correo: guribe@uniquindio.edu.co

\section{Para citar este artículo}

Rodríguez-Turriago, K. L., Camargo-Martínez, Z. y Uribe-Álvarez, G. (2022). La lectura del libro álbum como mediación hacia el desarrollo socioemocional. Folios, (55). https://doi.org/10.17227/folios.55-12657 


\title{
Resumen
}

El presente artículo de revisión examina la relación entre la comprensión de textos narrativos literarios (libro-álbum) y el desarrollo de habilidades socioemocionales en niños de educación básica primaria. El objetivo de este artículo es determinar si en efecto existe esta relación y cuál es su influencia en los procesos de aprendizaje de la literatura; de igual manera, presenta el estudio de 50 textos académicos, localizados, fundamentalmente, en el contexto hispanohablante durante los últimos 20 años. La metodología implementada para la búsqueda se basó en la consulta estratégica de fuentes, así como en los criterios de validez del corpus documental. Tras estas consideraciones, emergen tres categorías principales: libro-álbum (18), competencia literaria (19), competencia emocional y educación (13). Del análisis realizado, se desprende la necesidad de vincular la literatura infantil con la mediación del libro-álbum y el desarrollo de las habilidades socioemocionales en los niños, con la perspectiva de estimular algunas actitudes que les ayuden a comprenderse a sí mismos y a su entorno, desde lo afectivo, lo estético, el goce y el placer por la literatura.

\section{Palabras clave}

competencias para la vida; análisis literario; libro infantil; literatura; ciencias de la educación

\begin{abstract}
This review article examines the relationship between the understanding of literary narrative texts (book-album) and the development of socio-emotional skills in children of primary basic education. The objective of this article is to determine if this relationship does indeed exist and what is its influence on the learning processes of literature. In the same way, it presents the study of 50 academic texts located in the Spanish-speaking context during the last 20 years. The methodology implemented for the search was based on the strategic consultation of sources, as well as on the validity criteria of the documentary corpus. After these considerations, three main categories emerge: book-album (18), literary competence (19), emotional competence, and education (13). From the analysis carried out, it emerges the need to link children's literature with the mediation of the bookalbum and the development of socio-emotional skills in children to stimulate reflection and the transformation of some attitudes that help them understand each other, themselves and their environment, from the affective, the aesthetic, the enjoyment and

\section{Keywords}

life skills; literary analysis; picture-books; children's literature; educational sciences

Este artigo de revisão, examina a relação entre a compreensão de textos narrativos literários (livro-álbum) e o desenvolvimento de habilidades socioemocionais em crianças do ensino fundamental. 0 objetivo do texto é determinar se essa relação realmente existe e qual sua influência nos processos de aprendizagem da literatura. Da mesma forma, apresenta 0 estudo de 50 textos acadêmicos, localizados, principalmente, no contexto da língua espanhola durante os últimos 20 anos. A metodologia implementada para a pesquisa baseou-se na consulta estratégica de fontes, bem como nos critérios de validade do corpus documental. Após essas considerações, emergem três categorias principais: livro-álbum (18), competência literária (19), competência emocional e educação (13). A análise realizada, revela-se a necessidade de vincular a literatura infantil à mediação do livro-álbum e ao desenvolvimento de competências socioemocionais nas crianças, com a perspetiva de estimular algumas atitudes que os ajudem a compreender-se a si próprios,ao seu ambiente, desde o afetivo, o estético, o gozo e o prazer pela literatura.
\end{abstract}

Abstract pleasure of literature.

\section{Resumo}

\section{Palavras chave}

competências para a vida; análise literária; livros infantis; literatura; ciências da educação 


\section{Introducción}

Hablar de formación literaria nos permite profundizar en aquello que nos hace humanos: nuestro conocimiento, emociones y habilidades sociales. Al respecto, T. Colomer (2008) afirma que

La literatura ofrece unas cualidades formativas -estéticas, cognitivas, afectivas, lingüísticas, etc.- que permiten afirmar que el objetivo de la educación literaria es, en primer lugar, el de contribuir a la formación de la persona, formación indisolublemente ligada a la construcción de la sociabilidad y realizada a través de la confrontación con textos que explicitan la forma en la que las generaciones anteriores y las contemporáneas han abordado y abordan la valoración de la actividad humana. (p. 71)

A partir de esta apreciación, entendemos que la educación literaria también contempla lo emotivo. Mendoza (2004) sostiene que "el objetivo esencial y genérico de la formación y educación literaria de los alumnos [...] tiene un doble carácter integrador: aprender a interpretar y aprender a valorar y a apreciar las creaciones de signo estético-literario" (p. 15). Desde esta perspectiva, comprender un texto trasciende el análisis estructural y se desplaza hacia la búsqueda de formar lectores de literatura que puedan interpretar los significados que se derivan del discurso literario.

Acorde con lo anterior vemos la necesidad de vincular la literatura infantil y el desarrollo de habilidades socioemocionales, a través del libro-álbum como mediación pedagógica y didáctica, con el propósito de consolidar competencias tanto de tipo cognitivo como emocional. Justamente, este artículo de revisión, que surge de una tesis doctoral en construcción, busca favorecer la comprensión del libro-álbum como estrategia para el desarrollo de habilidades socioemocionales en estudiantes de Educación Básica Primaria. Por tanto, da cuenta de algunas investigaciones abordadas en los ámbitos nacional e internacional, que aportan información necesaria y relevante en el proceso de búsqueda de antecedentes.

En este orden de ideas, la indagación tuvo en cuenta tres características referentes a la consulta estratégica de fuentes, tal como lo sugieren $\mathrm{M}$. Cisneros-Estupiñán y G. Olave-Arias (2012): pertinencia, pluralidad y credibilidad. Para ello, acudimos a diferentes bases de datos atendiendo a fuentes confiables y de fácil acceso: Dialnet, Unirioja, Scielo, Mendeley, Redalyc, Academia, Google Scholar, repositorios de universidades colombianas: Universidad del Valle, Universidad Santiago de Cali, 
Universidad Nacional de Colombia, Universidad Distrital, como también repositorios de universidades internacionales: Universidad de Barcelona, Universidad de Navarra, Universidad Autónoma de Barcelona; revisión que se adhiere a los planteamientos de Gómez-Mendoza et al. (2010, p. 78), cuando proponen los criterios de validez del corpus documental en lo referente al acceso a las fuentes, que determina citar a los autores primarios, a partir de sus propios trabajos originales. Bajo este planteamiento, se deriva la información de fuentes como tesis de doctorado, trabajos de grado de maestría y artículos de investigación albergados en revistas académicas.

Asimismo, estos autores proponen el uso de fragmentos recientes del corpus, con referencia al criterio de actualidad que, para nuestro caso, se basa en investigaciones realizadas desde el 2002 hasta el 2020. De igual manera, la historicidad como criterio de validez, se refrenda en la autenticidad de los textos que son sometidos a un proceso de juicio de expertos. La exhaustividad, como último criterio de validez, se visibiliza en la selección del corpus, que se centró principalmente en investigaciones de estudio posgradual (maestrías y doctorados) y en artículos de investigación.

Durante el proceso de búsqueda se tuvo en cuenta que las investigaciones se ciñeran a estudios realizados en los niveles de educación infantil y básica primaria, que se enfocaran en la literatura infantil, especialmente en el libro-álbum como recurso didáctico (criterios de inclusión) y que tuvieran en cuenta las competencias emocionales. Estudios de pregrado y especializaciones no fueron fuente de consulta durante el proceso de búsqueda. También se excluyeron investigaciones sobre literatura juvenil e investigaciones que no abordaran la literatura desde el uso del libro-álbum (criterios de exclusión); estos criterios fueron utilizados tal como lo sugiere Manchado Garavito "se aplicarían los criterios de inclusión y exclusión, describiéndose claramente este proceso junto con el mecanismo de detección y eliminación de estudios duplicados" (2009, pp. 12-19).
Para tal efecto, y en razón de lo encontrado en los diferentes proyectos de investigación de maestría y doctorado y en algunos artículos, agrupamos el corpus documental de cincuenta textos académicos que sirven de apoyo a esta revisión, en tres grandes categorías: Libro-álbum; Competencia literaria; y Competencias emocionales y educación.

\section{Libro-álbum}

Dentro de esta categoría agrupamos las investigaciones que se valen del uso del libro-álbum como recurso didáctico para potenciar la competencia literaria en los niños. Es importante resaltar que este objeto artístico (Consejo, 2011) exige de sus lectores habilidades para interpretar la gramática visual propia de este género narrativo, que exalta la riqueza de las imágenes y se acompaña del texto escrito, convirtiéndose en una sola narración, algo así como una simbiosis narrativa ${ }^{1}$ en la que el texto depende de la imagen y la imagen del texto. Se trata de dieciocho investigaciones que agrupamos en cuatro tendencias, así:

Investigaciones en torno a la provocación por la lectura, investigaciones en torno a la comprensión e interpretación, investigaciones en torno a la oferta $\mathrm{y}$ mercado editorial e investigaciones en torno a las actitudes y valores que fomentan. A continuación, presentamos cada una de las tendencias.

\section{Investigaciones en torno a la provocación por la lectura}

La investigación de Valencia (2018) sostiene que el libro-álbum potencia la lectura de imágenes y de palabras, y así promueve los aprendizajes literarios, mediante la construcción de sentido que estos dos códigos producen. También, Dueñas Lorente y Barreu Rivas (2018) afirman que el papel del texto y la image requieren de un lector que active mecanismos de lectura que involucren otra manera de leer (espacialidad), otro modo de interpretar (texto-imagen) y un rompimiento con la tradición canónica de la literatura.

1 Definición propia que hace referencia a la relación interdependiente entre texto e imagen. 
Al respecto, Silva-Díaz (2003) asegura que esta forma de lectura proporciona conocimiento y experiencia a los primeros lectores de un modo en que la tradición canónica de la literatura infantil no lo hace. Esta nueva manera de leer permite que lector y texto estén en constante diálogo; este proceso implica una lectura activa, que al ser dinamizada por metodologías como la de A. Chambers (2008) desencadenan una actividad lectora altamente motivante al proponer al niño una serie de preguntas que conducen a una conversación literaria en la que el lector interviene de dos maneras: como hablante activo y como un oyente que, efectivamente, escucha lo que dicen los otros. Una vez el niño se siente motivado, se despierta en él un deseo de saber, un placer por la lectura. Al respecto, Vásquez (2019) plantea que la relación interdependiente entre texto e imagen le permite [al niño] complementar esa discontinuidad de códigos, al hacer uso de sus experiencias previas en la construcción de los "espacios vacíos" que él mismo debe consolidar.

Otra investigación que coincide con estas ideas es la de Sepúlveda (2016), quien asegura que el libro-álbum estimuló el gusto por la lectura al favorecer la imaginación, gracias a la abundancia de imágenes en estos textos. De igual manera, Infante (2018) reconoce la imagen como un elemento de la narración que permite capturar el interés del niño. También, este objeto artístico fomenta la lectura activa y acogedora, amena, tranquila, reflexiva y emocionante, como afirma Maldonado (2013). Los beneficios para el lector literario son múltiples, pues como se dijo, este tipo de textos requiere de un lector hábil que interprete, infiera y comprenda historias, tal como lo expone Plazas (2019). Estas habilidades se desarrollan mediante el contacto con esos dos tipos de lenguaje que confluyen, y que, asimismo, exigen un dominio gramatical y visual para asimilar lo que la materialidad del libro-álbum (portada, guardas y doble página, entre otros), aporta a la plena comprensión de la historia narrada.

Investigaciones en torno a la comprensión e interpretación

Las siguientes investigaciones se ocupan de los procesos de comprensión e interpretación y recurren al libro-álbum como mediación. Una de ellas, realizada por Arizpe y Styles (2002), comprueba que los niños son capaces de construir sentido desde elementos visuales tales como el color, la línea, los diseños, las metáforas y las bromas visuales. Valencia y Rodríguez (2019) sostienen que los niños leen de diferente manera imágenes y palabras, acción que implica "llenar vacíos" lexicales y semánticos, que pueden interrumpir el proceso de comprensión; pero el parafraseo y la validación del componente ficcional coadyuvan a los mecanismos de recepción del libro-álbum, lo que permite superar las dificultades de comprensión. En ese mismo sentido, Silva-Díaz (2005) apela por el reconocimiento de la variación - tensión entre lo canónico y su vulneración-, "el descubrimiento de una intencionalidad y la construcción de un conocimiento sobre la literatura y su funcionamiento como elementos clave para la comprensión cabal de las narraciones metaficcionales" (p. 492).

Ahora bien, los niños tienen un saber implícito de modos de leer no solo el texto sino también su entorno, según algunas investigaciones reseñadas, como las de Melo (2014), quien invita a que, a partir del entorno, se enseñe la alfabetización multimodal y se profundice en la lógica de la imagen, para que los niños logren trascender el modo como elaboran la comprensión de este tipo de textos, ya que ellos realizan la interpretación de manera independiente: por un lado, el texto y, por el otro, la imagen. En ese mismo sentido, Barrena (2010, p. 63) aborda la lectura digital en soporte hipermedia y sostiene que "el lector debe poseer una competencia literaria, en la que estén almacenados los referentes clave (hipotextos $\left.{ }^{2}\right)$. Además, apoyado en Mendoza (2010), reafirma que debe disponer de "un intertexto lector capaz de relacionar, asociar, comparar, contrastar, matizar y establecer correlaciones, y dependencias con versiones actualizadas en la literatura (hipertexto $\left.^{3}\right)$ " (p. 8).

2 Texto $A$ del que se deriva un texto $B$.

3 Texto $B$ creado a partir de un texto $A$ 
Investigaciones en torno a la oferta y el mercado editorial

Debido a que el volumen de obras publicadas es bastante amplio, se pueden encontrar en el mercado libros-álbum con calidad literaria, como otros que no la tienen. Es preciso, entonces, hacer una selección del corpus para garantizar que realmente motive y despierte el interés por la literatura.

En cuanto a la materialidad del libro-álbum, Larragueta (2019) en una investigación sobre la producción española de 69 libros-álbum en total, descubrió la prevalencia de ilustraciones con colores saturados, lo que tiende a provocar sensaciones de placer y vitalidad en el lector. Así mismo, encontró que el nivel de detalle en las ilustraciones es una herramienta a disposición del creador para comunicar el significado que busca. Estas características podrían estar conformando la canonicidad del libro-álbum infantil español en el mercado editorial actual.

En cuanto a la estructura interna de las narraciones - marcos temporales y espaciales para la acción; el tema, la trama, el argumento; los personajes con sus caracteres y caracterizaciones- y las nuevas formas del humor, Bellorín (2015) nos guía acerca de cómo los cuentos de hadas ilustrados contemporáneos van transformándose; esto implica que "aunque los personajes siguen siendo príncipes, princesas, brujas o hadas, ya no actúan como tal [sic]" (p. 188), sino que sus acciones evocan otras formas de problematizar la realidad. En palabras de la autora, "es común que en la reescritura de los cuentos de hadas, los conflictos de los personajes remitan a lo familiar, situaciones propias del hogar y del mundo infantil" (p. 189). De esta manera, la intención de estas narraciones se aterriza al plano de lo que el niño experimenta en su casa, en la escuela y con las personas cercanas a él.

En suma, la abundancia en la oferta editorial requiere, por parte del mediador de literatura, una rigurosa selección de obras que ofrezca a los niños el goce de una experiencia literaria de calidad. Para ello, es necesario estar atentos al "encantamiento" por la materialidad del libro, frente a la calidad de su contenido. También es importante tener presente la inclusión de obras clásicas en versiones actuales para los niños, ya que como indica Colomer (2008) "a través de la literatura, los niños pasan a compartir unos referentes lingüísticos, artísticos y culturales que les permiten relacionarse con las generaciones anteriores y les inscriben en su cultura” (p. 10).

\section{Investigaciones en torno a las actitudes $y$ valores que fomentan}

La literatura es una de las mejores aliadas para estimular la empatía de manera lúdica, además conduce a crear el hábito lector, ofrece herramientas para potenciar la imaginación y la creatividad, y posee un valor educativo innegable para el desarrollo socioafectivo infantil. Esta idea la sostienen Rodríguez y Vara (2019) en una investigación sobre la "fantasía" en el libro-álbum, en la que descubrieron que esta se pone al servicio de una "transición personal", en la medida en que resulta útil para enfrentar momentos vitales dolorosos; por ejemplo: los propios miedos, la reafirmación ante las burlas, el saber pedir perdón, entre otros.

En esa misma línea, Villegas (2010) expresa que la lectura compartida aporta un sentido formativo a los lectores; por ejemplo, al leer de forma conjunta el libro-álbum El pato y la muerte (Erlbruch, 2007) se puede reflexionar acerca de la "vida y la muerte" y crear una asociación afectiva explícita entre los lectores. De igual manera, Reyes y Vargas (2009) sostienen que cuando se posibilitan espacios de lectura compartida, los niveles de comprensión lectora se potencian, los niños pueden expresarse libremente en temáticas relacionadas con su entorno, su familia y sus vivencias, lo que lleva a una profunda reflexión de su realidad, mediante la experiencia literaria.

\section{Competencia literaria}

En este apartado incluimos las investigaciones que tienen como objetivo indagar sobre los procesos de comprensión literaria. Encontramos diecinueve investigaciones que decidimos agrupar bajo cuatro líneas: experiencia estético-literaria, lectura mediada y competencia emocional, conocimientos y competencias literarias, y nuevas formas de leer. 


\section{Experiencia estético-literaria}

Existen en la enseñanza de la lectura literaria algunos enfoques metodológicos centrados en la instrumentalización (técnica) de las funciones del lenguaje, $y$ aunque esto es importante, no es suficiente para acercar al niño a la literatura. Esta "excesiva formalidad de la lengua", tal como lo sugiere Álvarez (2011), deja por fuera conexiones personales entre el lector y el texto. Investigadores como Suárez (2014) proponen volver la mirada hacia el lector, hacia el sujeto que lee, ir más allá de las estrategias centradas en el uso instrumental del texto. En su investigación, encontró que "entre más elementos del texto tengan relación con el capital de experiencia del lector, más se estimula su imaginación y, por ende, las redes afectivas de conexión con la lectura se ponen en funcionamiento" (p. 226). Sostiene que cuando el niño establece relación entre el contenido y sus experiencias de vida, surge en él una mirada estética. En ese mismo sentido, Beltrán y Parra (2015) reafirma el hecho de que "la literatura infantil refleja nuevas realidades alrededor de experiencias y su interpretación genera espacios comunicativos para adquirir conocimientos, disfrutar la lectura literaria y construir nuevos significados" (p. 122).

En ese orden de ideas, Yubero y Larragaña (2010) aconsejan el acercamiento temprano del libro al niño, para así tratar de construir una relación placentera, que le proporcione valor lúdico y disfrute. Es muy significativa la importancia de que el primer acercamiento a la literatura esté envuelto por el buen humor; por ello, investigadores como Troncoso y Navarro (2019) corroboran que el humor dentro de una obra infantil provoca interés, motivación, alegría, sorpresa en el lector; es decir, toca en el niño aspectos emocionales que le permiten comprender de manera agradable la intención con la que el autor ha escrito el texto. En esa misma línea, Calvo (2011) sustenta que el humor en las obras despierta deseo por leer y desarrollo de la imaginación. Explorar historias que tratan temas como la muerte, la autoridad y el papel de la mujer en la sociedad permite emocionarse con el lenguaje literario.
Por otro lado, y sumamente relevante, Puerto (2015) alude al arte del cual hace gala el libro-álbum "como facilitador de espacios de socialización, de reunión, de goce y disfrute, en el que cada línea, color y textura responden a sensaciones que remiten a una situación; por ello, la experiencia visual es fundamental para la comprensión del entorno" (p. 67).

\section{Lectura mediada y competencia emocional}

La presencia de un mediador puede expresar facialmente el reconocimiento de una emoción y nominar las expresiones emocionales desde el mundo de la ficción. Al respecto, Riquelme (2011) hace referencia a la relación que se establece entre el mundo real y el ficticio, que se conectan a través de la lectura mediada. Esta relación enriquece la comprensión lectora y permite profundizar en otros aspectos de la experiencia humana, esto es, la exploración de los estados emocionales del otro; además, "le entrega al niño lector los espacios para el reconocimiento de un mundo emocional propio, que muchas veces permanece invisible hasta que algún elemento de la ficción lo pone al descubierto" (p. 190). Esta lectura mediada, la mayoría de las veces compartida, ayuda al lector, en palabras de Fittipaldi (2008), a otorgar sentidos nuevos a la lectura y a comprender diferentes puntos de vista, lo cual lleva a ponerse en el lugar del otro para, de este modo, alcanzar la empatía.

Respecto de estas expectativas, Munita (2014), en un estudio interesado en reconstruir los sistemas de creencias de maestros y estudiantes de magisterio, expone su profunda preocupación ante la ausencia de saberes sobre estos temas en los discursos de los maestros y su falta de conocimiento didáctico, que dificulta los procesos de innovación y mejora en el campo de la lectura literaria. Por eso, la escasa formación didáctica en este campo sigue perpetuando métodos como reconstruir el argumento o responder preguntas de acuerdo con lo leído. Para Munita, las experiencias previas de lectura, la variedad de su enciclopedia literaria, las creencias y prácticas que se vivencian en el contexto institucional son condicionantes que permean la enseñanza de la educación literaria. Se requiere, entonces, de un maestro con un alto "bagaje lector", es decir, con 
una robusta competencia literaria para que sea un mediador eficiente.

\section{Conocimientos y competencias literarias}

El niño desarrolla ciertas habilidades que le permiten ser un lector competente en el tiempo. La literatura es el campo que le proporciona el conocimiento de distintas obras y fortalece su intertexto lector. En este sentido, Hoyos y Gallego (2017) consideran que la variedad textual contribuye al perfeccionamiento de las habilidades lectoras y genera aportes significativos en los niveles conceptual y cultural de los sujetos (p. 43).

En consonancia con la anterior investigación, Lozano (2013) sustenta su estudio en cinco de las diez claves propuestas en la teoría de la respuesta lectora: hipertexto, soporte, inferencia, voz narrativa y metaficción. Asegura que la clave que le permite al niño incursionar en la comunidad cultural es $e l$ hipertexto, al ser capaz de establecer las conexiones existentes entre un libro-álbum y diferentes textos de la tradición popular.

En este orden de cuestiones, la comprensión literaria constituye un factor fundamental para el desarrollo del hábito lector, pero la motivación y el gusto sostienen el hábito en el tiempo. Una de las claves mencionadas en el párrafo anterior alude a la metaficción, clave literaria que puede provocar esa perpetuación, ya que a través de ella, los niños aprenden el funcionamiento de la literatura de una manera lúdica y didáctica al descubrir el sentido de la narración, lo que permite mayor comprensión y, por lo tanto, un interés prolongado en el tiempo. Así lo explica Silva-Díaz (2003) cuando dice que

La metaficción impulsa al lector a levantarse de su butaca de terciopelo rojo desde la que, absorto, contemplaba el drama, lo guía para que se mueva tras bambalinas y observe con distancia la tramoya y demás parapetos que rodean la escena. (p. 176)

No obstante, Valdés (2013) descubre, que a pesar de que algunos estudiantes presentan altos niveles de comprensión lectora, no necesariamente desarrollan hábitos lectores a lo largo de su vida. Para que los niños asuman la literatura como un espacio lúdico y de reflexión sobre los saberes representados en los textos, deben sentir un deseo por conocerla. Al respecto, Fittipaldi (2013) encontró que

A pesar de que el reconocimiento de los planos de la realidad y la ficción son uno de los objetivos estudiados por la teoría literaria y la teoría del arte, y que conforman una fuente de interés para los niños, estos no son abordados en los estudios de didáctica, ni en los programas escogidos para el análisis propuesto en su investigación. (p. 449)

De hecho, las dimensiones afectivas, socioculturales e interpretativas emergen de manera recurrente en los diseños, a diferencia de los aspectos éticos y estéticos de los textos literarios, a los cuales no se les presta la atención necesaria.

También, un estudio realizado por Ramos y Crespo (2008) establece una estrecha relación entre la teoría de la mente y la comprensión lectora, en la que

resalta la importancia de comprender el mundo intencional de los otros y de metarrepresentar sus estados mentales - por ejemplo, entender qué es lo que piensan los personajes-, como una de las condiciones fundamentales para lograr una comprensión de los textos narrativos. (p. 59)

Por lo tanto, cuando el niño logra entender el porqué de ciertos comportamientos en el personaje y los compara con situaciones que él ha experimentado, se consigue un mayor entendimiento y comprensión de la obra literaria, que al ligarse con su propia experiencia de vida, le concede una valía afectiva y emocional.

\section{Nuevas formas de leer}

Modos actuales de acercamiento a la lectura y a la literatura se dejan entrever en la práctica de su enseñanza y, ante todo, de su aprendizaje. El advenimiento tecnológico ha desencadenado nuevas formas de leer que, desde la multimodalidad, convocan a una transformación de la práctica lectora, que se concebía como el acto de pasar la vista en un movimiento de izquierda a derecha. El posicionamiento de la imagen, en la actualidad, constituye el motor de cambio que invita a una transformación 
del lector y del acto de leer. En concordancia con este planteamiento, Consejo (2011) realizó una investigación en la cual analizó en profundidad el libro-álbum desde los peritextos ${ }^{4}$ y argumentó que este "objeto artístico" está configurando un nuevo lector, desde las guardas, que establecen una relación directa entre la nueva cultura de la imagen y el modelo lector actual, capaz de interpretar las imágenes que se incorporan en el discurso.

Siguiendo esta misma idea, Gomes-Francoe-Silva (2019) asegura que es necesario educar la mirada para la lectura de imágenes desde edades tempranas; en otras palabras, alfabetizar a los más pequeños en la lectura de signos lingüísticos y mensajes icónicos, para que así puedan interactuar de manera crítica y eficaz con los signos que les rodean.

Estas formas de leer permiten inferir un nuevo concepto de literatura, que requiere de una herramienta que se acerque a los intereses de los niños, que movilice en ellos no solo conocimientos, sino, además, el placer y el acercamiento a lo estético. Sin lugar a dudas, y como se ha mencionado en este artículo, el libro-álbum cumple con esos requerimientos. La exploración de un número significativo de investigaciones, como la de Ruiz (2014), sugiere que el libro-álbum metaficcional permite a los lectores realizar inferencias e interpretaciones cada vez más complejas, les brinda las estrategias necesarias para desarrollar su competencia literaria y promover la reflexión metaliteraria.

Una habilidad altamente potencializada a través de la lectura de la metaficción es, quizá, la puesta en funcionamiento de la activación de su intertexto lector; dicho de otra manera, la competencia literaria se fortalece cuando el lector entra en contacto con un corpus amplio y variado de literatura. Paralelamente, otro de los factores determinantes que favorecen esta competencia son las discusiones que en el nivel grupal se tejen en relación con las historias, ya que se

4 El autor se refiere a las guardas impresas con colores, imágenes, símbolos o patrones repetidos que permiten adentrarse en el mundo creado en la obra. Las guardas presentan una gran variedad de formas y cumplen diferentes funciones. produce retroalimentación y se hace de la literatura una experiencia compartida.

\section{Competencias emocionales y educación}

En este apartado compilamos trece investigaciones que han examinado de manera directa las competencias emocionales en el acto educativo y que pueden agruparse por su proximidad temática bajo tres tendencias: emoción y escuela, literatura e inteligencia emocional y desarrollo socioemocional.

\section{Emoción y escuela}

Hacer de la escuela un espacio propicio para el aprendizaje evoca una reflexión sobre cómo este escenario permite u obstaculiza el desarrollo de competencias socioemocionales. Se supone que el contexto escolar debe favorecer la inclusión, el respeto por la diferencia y la mediación de los conflictos. Diversas investigaciones sobre este asunto sugieren promover y facilitar en los niños la adquisición de habilidades sociales en el entorno escolar, con la intención de formarlos en el manejo de sus propias emociones. Camacho et al. (2017) encontraron una fuerte relación entre inteligencia emocional y convivencia escolar, en la que ratifican la necesidad de ofrecer a los estudiantes, nuevas posibilidades de relaciones que lleven a la reflexión cuando se solucionan conflictos entre pares. Los resultados sugieren la integración de la educación socioemocional al currículo y el otorgamiento de un equilibrio frente a la dimensión cognitiva.

En ese orden de ideas, el currículo debe gestionarse para hacer realidad estos aprendizajes, pero también la intervención en el aula y las relaciones humanas que ahí se dan. Al respecto, Abarca (2003) encontró que algunos objetivos de la educación emocional están presentes en los diseños curriculares; sin embargo, su estructuración y organización no parecen seguir una secuencia lógica y fundamentada por los conocimientos teóricos y empíricos que se disponen sobre el desarrollo emocional.

Las tendencias señalaron que la formación de los docentes evidencia su falta de conocimiento en educación emocional, tanto en el currículo como 
en la práctica educativa. Uno de los aspectos de mayor insistencia en la escuela es el interés por mantener el "orden" dentro de la clase. Otro de los hallazgos encontrados hace referencia a que el docente aprovecha sus competencias emocionales para relacionarse con el alumno, pero no promueve en él esas mismas competencias para que las use autónomamente. En relación con esta investigación, Calderón Rodríguez et al. (2014) consideran que "las habilidades emocionales, afectivas y sociales deben ser enseñadas por un equipo docente que domine estas capacidades, ya que las aulas son para los niños modelos de aprendizaje socioemocional" (p. 20). En síntesis, en la investigación reseñada se da cuenta de un insuficiente conocimiento sobre nuevas herramientas para la gestión emocional por parte de los docentes, ya que se enseña y se actúa desde el conocimiento empírico que ellos poseen.

\section{Literatura e inteligencia emocional}

La literatura es una práctica liberadora que ayuda a dar sentido a la vida, este es un pensamiento de Sanjuán y Senís (2016), quienes aseveran que "las dimensiones éticas e intelectuales de la literatura deberían ser inseparables de las estéticas y emocionales, si se quiere recuperar el potencial formativo" (p. 17). Estos investigadores realizaron un análisis en cinco textos autobiográficos del mismo número de escritores españoles contemporáneos e hicieron los siguientes hallazgos:

- La práctica de la lectura de ficción promueve la creatividad, establece una vía alterna de asimilación del conocimiento.

- El modo tradicional de enseñar literatura no acoge el factor emocional, que debe ser considerado como un componente inherente al lector.

- Los lectores entienden los textos según su experiencia de vida.

Con base en estas conclusiones, los autores sugieren que los niños tengan acceso a una gran diversidad de libros para facilitar el encuentro con la literatura.
En concordancia con la anterior investigación, Dos Santos y Franco (2014) pretendieron establecer la relación entre inteligencia emocional y el número de libros leídos a partir de esta idea de Chartier (1999):

La lectura es fundamental para la construcción del conocimiento emocional y las actividades de lectura realizadas en la escuela no son solo útiles por la repetición del proceso de lectura, sino fundamentalmente por la interiorización que provocan en el individuo y para la formación de su conciencia social. (p. 163)

A mayor cantidad de libros leídos, mayor vocabulario y disposición para leer, no solo en la escuela sino en los tiempos libres. Con respecto al aumento de la variación en el vocabulario, Vargas-García et al. (2020) aseguran que la lectura dialógica incrementa procesos cognitivos como el lenguaje expresivo y el lenguaje comprensivo que, generalmente, dotan al lector de un mejor y más amplio vocabulario. Además, los citados investigadores manifiestan que la mediación de un adulto en los procesos de lectura permite establecer relaciones interactivas porque da lugar a la participación de los niños y los conduce a la optimización de sus habilidades lingüísticas y cognitivas.

Como se ha mencionado, las emociones tienen un rol fundamental en los procesos de aprendizaje, en la calidad de las relaciones sociales y en el rendimiento académico. De ahí nuestra afinidad con los planteamientos de Ramos (2014), quien declara que la literatura infantil ayuda a formar personas seguras de sí mismas, con gran autoestima, capaces de amarse, aceptarse y valorarse. Por todo ello, la literatura infantil es facilitadora del mejoramiento del ambiente en el aula.

Asimismo, Alzola (2007), en una investigación que parte del análisis del libro Tener amigos es divertido (Lewis, 1999), indica que se necesitan experiencias a veces dolorosas para cambiar actitudes negativas en las personas. La narración plantea que la amistad es un aprendizaje social e implica apertura al otro. Demuestra cómo "la importancia de la consolidación de la historia, la 
solidez de los personajes, lo figurativo, lo temático, las identificaciones que provoca, las emociones que suscita, son elementos importantes en el análisis literario y axiológico de una narración" (p. 163). Los personajes bien construidos, tanto principales como secundarios, son siempre modelos de vida. Así las cosas, la lectura requiere la activación de procesos cognitivos y socioemocionales en el aula $y$, adicionalmente, habilidades lectoras y metacomprensivas. En ese sentido, Mengual (2017) resalta la importancia de la labor docente en el fomento de la educación emocional, como factor amortiguador del estrés académico y como vehículo para una mayor implicación en el aprendizaje.

\section{Desarrollo socioemocional}

La alfabetización emocional constituye un pilar fundamental en la educación de los niños; por ello, la escuela se asegura de que aprendan lecciones esenciales para su vida. Con esto, la función de la escuela no se agota en la enseñanza de los contenidos, sino que, además, se interesa por el sentir de los estudiantes, por sus reacciones, porque se sientan valorados y respetados y, en consecuencia, actúen conforme a ello. Al respecto, Barrios-Tao y Peña (2019) consideran las experiencias emocionales como un factor esencial en las acciones educativas y advierten que el desafío para todos es profundizar en la conciencia, la comprensión y la formación acerca de las emociones.

Durante la exploración de estas investigaciones, se encuentra una tendencia que cuestiona la forma como los maestros estamos llevando a cabo esta tarea. Por ejemplo, Berger et al. (2009) concluyen que existe una gran preocupación por temas relacionados con la autoestima y las habilidades sociales, pero es evidente la ausencia de herramientas, tanto docentes como institucionales, para favorecer el bienestar socioemocional. Dentro de este contexto, Roque (2018) insiste en la necesidad de una formación académica urgente y profunda para los docentes, que garantice una orientación adecuada para sus estudiantes. Igualmente, destaca la importancia de llevar al aula actividades cercanas a las vivencias de los estudiantes, para que encuentren el sentido de las tareas que se proponen en clase.

\section{Conclusiones}

Un sistema educativo que favorezca el vínculo entre los procesos cognitivos y los emocionales posibilita la formación integral del ser humano. La literatura infantil, sin lugar a dudas, permite esa integralidad, si se tienen en cuenta aspectos de tipo emocional que ayuden a potenciar los procesos cognitivos. Es tarea del maestro acercar el libro al niño y que él lo reciba con deseos de descubrir lo que hay dentro. Al respecto, podemos sacar las siguientes conclusiones:

- En cuanto a la primera categoría de análisis, concebimos el libro-álbum como una mediación didáctica con características artísticas que logra llamar la atención del niño y que actúa como elemento activador de lectura. Debido a la materialidad que configura este objeto artístico es fundamental profundizar en la alfabetización de la gramática visual, ya que a partir de la comprensión de su simbiosis narrativa, se potencian las competencias literarias. Un alto porcentaje de las investigaciones exploradas en esta categoría acuden al libro-álbum centrando el objetivo de enseñanza en la comprensión y la interpretación literaria desde lo cognitivo, con una mención somera de los aspectos emocionales que el niño puede inferir. Conviene mencionar que de las dieciocho investigaciones citadas para esta categoría, ninguna contempla la posibilidad de establecer el vínculo entre la literatura y el desarrollo de las habilidades socioemocionales.

- En cuanto a la competencia literaria, nuestra segunda categoría, concluimos que el mediador cumple una función importante entre el libro y el niño; se convierte en el puente que permite la interconexión de emociones; genera la motivación, el gusto por leer y se vale del libro-álbum para lograrlo. Muchas de las diecinueve investigaciones situadas en esta categoría sugieren de manera reiterativa poner en práctica el uso del libro-álbum metaficcional; 
en primer lugar, por el interés que despierta en el lector; en segundo, porque permite reflexionar sobre el propio estado emocional y sobre los estados emocionales del otro; y tercero, porque requiere del lector el uso de diferentes competencias literarias, entre ellas, las inferenciales. Igualmente, es importante tener a disposición una gran variedad textual para el fortalecimiento del intertexto $y$, por ende, de las habilidades lectoras.

- Dentro de estas investigaciones se declara que, en la actualidad, se lee de una manera diferente - debido al posicionamiento de la imagen, no solo en esta clase de textos, sino también en el ámbito cultural-, y al hacerlo, irremediablemente se transforma al lector.

- Por otra parte, en el marco de las anteriores investigaciones, aunque se tienen en cuenta aspectos de tipo emocional que se vinculan de forma directa con la literatura, no se encuentran investigaciones que busquen, a través de ella, el despliegue o desarrollo de las habilidades socioemocionales, competencias tan importantes como las literarias.

- En nuestra última categoría, competencias emocionales y educación, se manifiesta cómo a través de la literatura los niños relacionan sus vivencias personales con las historias narradas en los textos y cómo esta experiencia cercana a su realidad puede ser transformadora y significativa para ellos. De hecho, la calidad en la selección de obras literarias que susciten reflexiones acerca de la vida, la muerte, los momentos vitales dolorosos o felices, es trascendente porque fomenta diferentes valores éticos. Sin embargo, la referencia a los valores éticos no es equiparable al desarrollo de las competencias emocionales, puesto que estas investigaciones no recurren a la literatura para desarrollar habilidades sociales, sino que la ven como un medio para enseñar valores, asunto que no es de nuestro interés investigativo. En otras palabras, pensamos la literatura como una de las mejores aliadas para estimular la imaginación y la creatividad, además de avivar aspectos interpersonales como la empatía, el autocontrol, la resolución de conflictos y las habilidades sociales imprescindibles por estos tiempos.

- Igualmente, a partir del análisis suscitado en estos estudios, emerge una notoria preocupación entre los diferentes investigadores, quienes coinciden en que la formación en competencias emocionales por parte de los maestros es limitada y, por consiguiente, los procesos de aprendizaje en torno a las habilidades de carácter socioemocional en los estudiantes no son los esperados. Del mismo modo, porque en el maestro recae la responsabilidad de construcción del ser humano, y en ese sentido, sus actuaciones, sus pensamientos, sus actitudes, su visión de mundo influyen de manera directa en su quehacer pedagógico.

- Esta recapitulación conduce a sostener que, durante la revisión exploratoria, no hemos encontrado estudio alguno que reconozca la comprensión del libro-álbum como una estrategia para el desarrollo de habilidades socioemocionales; se reconoce, sí, en la mayoría de las investigaciones, que los aspectos emocionales son importantes para el acercamiento del niño a la literatura, pero ninguna de ellas establece de manera sistemática el aprendizaje de estas habilidades como hilo conductor de la enseñanza. Esta situación da lugar al estudio de una temática que aún falta por profundizar en el campo de la enseñanza de la literatura infantil, en particular, en el género libro-álbum.

\section{Referencias}

Abarca, C. (2003). La educación emocional en la educación primaria: Currículo y práctica [tesis de doctorado]. Universidad Autónoma de Barcelona. http://hdl.handle.net/2445/42457

Álvarez, M. (2011). De la experiencia de la lectura a la educación literaria: Análisis de los componentes emocionales de la lectura literaria en la infancia 
y la adolescencia. Ocnos, Revista de Estudios sobre Lectura. (7), 85-100. https://doi.org/10.18239/ ocnos_2011.07.07

Alzola, N. (2007). Literatura infantil y educación ética: Análisis de un libro. Revista de Psicodidáctica, 12(1). https://ojs.ehu.eus/index.php/psicodidactica/ article/view/215/211

Arizpe, E. y Styles, M. (2002). ¿Cómo se lee una imagen? El desarrollo de la capacidad visual y la lectura mediante libros ilustrados. Lectura y Vida, 3, 21-29. http://www.lecturayvida.fahce.unlp.edu.ar/numeros/a23n3/23_03_Arizpe.pdf

Barrena, D. (2010). El álbum como hipertexto textual: Análisis de facetas que intervienen en su recepción [tesis de maestría]. Universidad de Barcelona http:// diposit.ub.edu/dspace/bitstream/2445/16782/1/ Daniela_Barrena_Medel_version_definitiva\%5b1\%5d.pdf

Barrios-Tao, H. y Peña, L. (2019). Líneas teóricas fundamentales para una educación emocional. Educación y Educadores, 22(3), 487-509. https://doi. org/10.5294/edu.2019.22.3.8

Bellorín, B. (2015). De lo universal a lo global: Nuevas formas del folklore en los álbumes para niños [tesis de doctorado]. Universidad Autónoma de Barcelona. https://ddd.uab.cat/pub/tesis/2015/ hdl_10803_311617/bvbb1de1.pdf

Beltrán, A. y Parra, F. (2015). Literatura infantil: Medio estratégico para el fortalecimiento, la consolidación de valores, crecimiento personal y convivencial en los estudiantes [tesis de maestría]. Universidad Distrital Francisco José de Caldas. http://repository.udistrital.edu.co/handle/11349/2095

Berger, C., Milicic, N., Alcalay, L., Torretti, A., Paz, A. M. y Justiniano, B.(2009). Bienestar socio-emocional en contextos escolares: La percepción de estudiantes chilenos. Estudios sobre Educación, 17, 21-43. https:// dadun.unav.edu/bitstream/10171/9839/3/17Eb.pdf

Caballero, P. y García, V. (2010). La lectura como determinante del desarrollo de la competencia emocional: Un estudio hecho con población universitaria. Revista de Investigación Educativa, 28(2), 345-359. https://revistas.um.es/rie/article/view/104331

Calderón Rodríguez, M., González Mora, G., Salazar Segnini, P. y Washburn Madrigal, S. (2014). El papel docente ante las emociones de niños y niñas de tercer grado. Actualidades Investigativas en Educación. https://www.redalyc.org/pdf/447/44729876009.pdf
Calvo, V. (2011). Claves para seleccionar un itinerario constructor de identidades en el proceso de acogida y aprendizaje del español como segunda lengua. Ocnos, Revista de Estudios sobre Lectura, 7, 123-135.

Camacho, N., Ordóñez, J. C., Roncancio, M. H. y Vaca, P. V. (2017). Convivencia escolar y cotidianidad: una mirada desde la inteligencia emocional. Educación y Desarrollo Social, 11(1), 24-47. https://doi. org/10/18359/reds.2649

Chambers, A. (2008). Conversaciones: Escritos sobre la literatura y los niños. Fondo de Cultura Económica.

Cisneros, M. y Olave, G. (2012). Redacción y publicación de artículos científicos: Enfoque discursivo. Ecoe Ediciones.

Colomer, T. (2008). "La constitución de acervos". En E. Bonilla, D. Goldin y R. Salaberría (coords.) Bibliotecas y escuelas: Retos y desafíos en la sociedad del conocimiento (pp. 378-405). Océano.

Colomer, T. (2009). La educación literaria. En C. Armendano e I. Miret, (coords.), Lectura y bibliotecas escolares: Metas educativas 2021 (pp. 71-82). EOI.

Consejo, E. (2011). Peritextos del siglo xxi: Las guardas en el discurso literario infantil. Ocnos, Revista de Estudios sobre Lectura, 7, 111-122.

Dos Santos, N. De Nóbrega y Franco, G. (2014). Inteligencia emocional y actividad lectora en una escuela de $1{ }^{\text {er }}$ Ciclo. International Journal of Developmental and Educational Psychology, 5(1),159-165. https://www.redalyc.org/articulo. oa? id=3498/349851788017

Dueñas Lorente, J. y Barreu, A. (2018). ¿ Nuevos públicos para el libro álbum?: Experiencias de recepción en educación primaria. AILIJ, Anuario de Investigación en Literatura Infantil y Juvenil, 16, 47-62. https:// revistas.webs.uvigo.es/index.php/AILIJ/article/ view/1339

Erlbruch, W. (2007). El pato y la muerte. Bárbara Fiore Editora.

Fittipaldi, M. (2008). Diversos lectores, diferentes lecturas: Cómo los niños inmigrantes y catalanes leen las metáforas en Emigrantes de Shaun Tán. En R. Ramos y A. F. Mosquera (eds.), Literatura Infantil y Juvenil y Diversidad Cultural / Literatura para a Infância e Juventude e Diversidade Cultural, (pp. 149-165). ANILIJ/CIEC-Universidade do Minho. https://www.academia.edu/4846387/ Literatura_Infantil_y_Diversidad_Cultural 
Fittipaldi, M. (2013). ¿Qué han de saber los niños sobre literatura?: Conocimientos literarios y tipos de actuaciones que permiten progresar en la competencia literaria [tesis de doctorado]. Universidad Autónoma de Barcelona. https:/ddd.uab.cat/pub/tesis/2014/ hdl_10803_131306/mf1de1.pdf

Gomes-Franco-e-Silva, F. (2019). Alfabetizar para ver: La importancia de aprender a leer, comprender y analizar imágenes. Ocnos, Revista de Estudios sobre Lectura, 18(3), 48-58. https://doi.org/10.18239/ ocnos_2019.18.3.2103

Gómez-Mendoza, M., Deslauriers, J. P. y AlzatePiedrahíta, M. (2010). Cómo hacer tesis de maestría $y$ doctorado. Ecoe.

Hoyos, A. y Gallego, T. (2017). Desarrollo de habilidades de comprensión lectora en niños y niñas de la básica primaria. Revista Virtual Universidad Católica del Norte, 51, 23-45. http://revistavirtual.ucn.edu.co/ index.php/RevistaUCN/article/view/841/1359

Infante, L. (2018). Implementación de una secuencia didáctica mediada por el libro-álbum para el desarrollo de habilidades comprensivas en niños del grado transición [tesis de maestría]. Universidad Industrial de Santander. http://noesis.uis.edu.co/ bitstream/123456789/32337/1/173061.pdf

Larragueta, M. (2019). El libro-álbum premiado: Análisis crítico de las ilustraciones en el panorama español 2000-2017. Prisma Social, 25, 299-315. https:// revistaprismasocial.es/article/view/2715

Lewis, R. (1999). Tener amigos es divertido. SM.

Lozano, S. (2013). El libro-álbum y el desarrollo de la competencia literaria: Análisis de respuestas lectoras con un grupo de niños de educación infantil y educación primaria [tesis de maestría]. Universidad Zaragoza. https://zaguan.unizar.es/record/30758/ files/TAZ-TFM-2014-954.pdf

Maldonado, M. (2013). Fomento de la lectura: Significado de una experiencia entre pares desde el libro-álbum [tesis de maestría]. Universidad Industrial de Santander. http://tangara.uis.edu.co/biblioweb/ tesis/2013/150740.pdf

Manchado, R., Tamames, S., López, M., Mohedano, L., D’agostino, M. y De Cabo, J. V.(2009). Revisiones sistemáticas exploratorias. Medicina y Seguridad del Trabajo, 55(216), 12-19. http:// scielo.isciii.es/scielo.php?script=sci_arttext\&pi$\mathrm{d}=$ S0465-546X2009000300002\&lng=es\&tlng=es
Melo, Á. (2014). Procesos de comprensión y producción de textos multimodales a través del libro-álbum. Folios de Humanidades y Pedagogía, 1(2), 37-56. http://revistas.pedagogica.edu.co/index.php/FHP/ article/view/2555

Mendoza, A. (2004). La educación literaria: bases para la formación de la competencia lecto-literaria. Ediciones Aljibe.

Mengual, E. (2017). Metacomprensión e inteligencia emocional: Relación e influencia en la comprensión lectora en alumnado de $5^{\circ}$ y $6^{\circ}$ de educación primaria [tesis de doctorado]. Universidad Complutense de Madrid. https://eprints.ucm.es/43467/

Munita, F. (2014). El mediador escolar de lectura literaria: Un estudio del espacio de encuentro entre prácticas didácticas, sistemas de creencias y trayectorias personales de lectura [tesis de doctorado]. Universidad Autónoma de Barcelona. https://ddd.uab.cat/pub/ tesis/2014/hdl_10803_313451/fm1de1.pdf

Plazas, T. (2019). El aula, un punto de encuentro sobre el libro-álbum: Una experiencia de promoción de lectura literaria [tesis de maestría]. Universidad Distrital Francisco José de Caldas. http://repository.udistrital. edu.co/handle/11349/15188

Puerto, M. (2015). Leer con imágenes, dibujar con palabras: La comprensión lectora mediada por el libro álbum [tesis de maestría]. Universidad Distrital Francisco José de Caldas. http://repository.udistrital.edu.co/bitstream/11349/2135/1/ PuertoRubioMarthaLiliana2015.pdf

Ramos, C. (2014). Literatura infantil como metodología para estimular el desarrollo emocional de los niños y niñas del subnivel 2 de Educación inicial [tesis de maestría]. Universidad Central del Ecuador. http:// www.dspace.uce.edu.ec/bitstream/25000/12617/1/ T-UCE-0010-065-2017.pdf

Ramos, C. y Crespo, N. (2008). Niños que leen, niños que comprenden intenciones: Relación entre la comprensión lectora y la teoría de la mente. Enunciación, 13(1), 53-60. https://doi. org/10.14483/22486798.1261

Reyes, L. y Vargas, A. (2009). La lectura como experiencia: Análisis de cuatro situaciones de lectura de libros-álbum en educación inicial docente [tesis de maestría]. Pontificia Universidad Javeriana. https://repository. javeriana.edu.co/bitstream/handle/10554/406/ edu35.pdf? sequence $=1$ \&isAllowed $=y$ 
Richard, S. (2006). Lanalyse de contenu pour la recherche en didactique de la littérature. Le traitement de données quantitatives pour une analyse qualitative: parcous d'une approche mixte. Recherches qualitatives, 26(1), 181-207.

Riquelme, E. (2011). La lectura mediada de la literatura infantil como herramienta para el desarrollo de competencias emocionales [tesis de doctorado]. Universidad Autónoma de Madrid. https://repositorio.uam.es/bitstream/ handle/10486/14319/66911_Riquelme\%20 Mella\%20Enrique.pdf? sequence $=1$ \&isAllowed $=y$

Rodríguez, R. y Vara, A. (2019). La fantasía en el álbum ilustrado infantil. Álabe, 20. 10.15645/ Alabe2019.20.5

Roque, R. (2018). Desarrollo personal y manejo asertivo de emociones en estudiantes. Episteme Koinonia. Revista Electrónica de Ciencias de la Educación, Humanidades, Artes y Bellas Artes, 1(2), 61-82. https://dialnet.unirioja.es/servlet/ articulo? codigo $=7276125$

Ruiz-Domínguez, M. (2014). Estrategias metaficcionales y respuestas lectoras: Estudio exploratorio. Ocnos, Revista de Estudios sobre Lectura, 11, https://ruidera. uclm.es/xmlui/handle/10578/16014

Sanjuán, M. y Senís, J. (2016). Literatura e identidad: Experiencias de lectura literaria en la infancia y adolescencia de cinco escritores españoles contemporáneos. Álabe, 15. 10.15645/Alabe2017.15

Selfa, M. (2015). Estudios científicos sobre literatura infantil y su didáctica: Revisión bibliográfica (20002014). Ocnos, Revista de Estudios sobre Lectura, 13 65-84.10.18239/ocnos_2015.13.04

Sepúlveda, H. (2016). Animación a la lectura en niños de preescolar y la interacción con sus familias a través del uso del libro-álbum [tesis de maestría]. Universidad Nacional de Colombia. http://bdigital.unal.edu. co/53159/1/hildamonicasepulvedacocunubo.2016. pdf

Silva-Díaz, M. (2003). “QQué libros más raros!”: Construcción y evaluación de un instrumento para describir las variaciones metaficcionales en el álbum. ANILIJ, Anuario de Investigación en Literatura Infantil y Juvenil, 1, 167-192. https://revistas.webs.uvigo.es/ index.php/AILIJ/article/view/728/713

Silva-Díaz, M. (2005). Libros que enseñan a leer: Álbumes meta-ficcionales y conocimiento literario [tesis de doctorado]. Universidad Autónoma de Barcelona. https://ddd.uab.cat/pub/tesis/2005/tdx-0621106000248/mcsdo1de1.pdf

Suárez, V. (2014). La lectura como experiencia estético-literaria. Enunciación, 19(2), 215-227. http://dx. doi.org/10.14483/udistrital.jour.enunc.2014.2.a03

Troncoso, X. y Navarro, M. (2019). Experiencias de lectura literaria en educación básica: Papelucho de Marcela Paz, un estudio de caso. Folios, 50, 97-110. 10.17227/Folios.50-10223

Valdés, M. (2013). ¿Leen en forma voluntaria y recreativa los niños que logran un buen nivel de comprensión lectora? Ocnos, Revista de Estudios sobre Lectura, 10, 71-89. https://revista.uclm.es/index.php/ocnos/ article/view/330

Valencia, M. (2018). La colección Semilla y la educación literaria para Básica Primaria en Colombia: Currículo, libro álbum y formación docente [tesis de doctorado]. Universidad Autónoma de Barcelona. tdx.cat/bitstream/handle/10803/665749/mvl1de1. pdf? sequence $=1$ \&is All

Valencia, M. y Rodríguez, D. (2019). Interacción icono-verbal y recepción de libros álbum: Desafíos de la lectura en básica primaria. Sophia, 15(1), 48-59. https://doi.org/10.18634/sophiaj.15v.1i.712

Vargas-García, V. A., Sánchez-López, J. V., DelgadoReyes, A. C., Aguirre-Aldana, L. y AgudeloHernández, F. (2020). La lectura dialógica en la promoción de perfiles cognitivos, emocionales y comportamentales en primera infancia. Ocnos, Revista de Estudios sobre Lectura, 19(1), 7-21. https:// doi.org/10.18239/ocnos_2020.19.1.1888

Vásquez, R. (2019). El libro-álbum como estrategia didáctica: Desde la práctica social del lenguaje en educación inicial [tesis de maestría]. Universidad Santiago de Cali. https://repository.usc.edu.co/ handle/20.500.12421/910

Villegas, F. (2010). Aproximaciones a un estudio del libro-álbum narrativo: Un caso práctico para la educación en valores en lectores adolescentes de Chile [tesis de maestría] Universidad de Barcelona. http:// diposit.ub.edu/dspace/bitstream/2445/16063/1/ VILLEGAS_trabajofinaldemasterf.pdf

Yubero, S. y Larrañaga, E. (2010). El valor de la lectura en relación con el comportamiento lector: Un estudio sobre los hábitos lectores y el estilo de vida en niños. Ocnos, Revista de Estudios sobre Lectura, 6, 7-20. 
